\title{
Coastal currents in the Eastern Gulf of Tehuantepec from coastal altimetry
}

\author{
J. Salazar-Ceciliano $^{\mathrm{a}, *}$, A. Trasviña-Castro ${ }^{\mathrm{b}}$, E. González-Rodríguez ${ }^{\mathrm{b}}$ \\ a Departamento de Física, Universidad Nacional (UNA), Avenida 1 y Calle 9, CP 86-3000 Heredia, Costa Rica \\ ${ }^{\mathrm{b}}$ Centro de Investigación Científica y de Educación Superior de Ensenada, Baja California (CICESE), Unidad La Paz, 334 Fraccionamiento Bella Vista, \\ CP 23050 La Paz, Baja California Sur, Mexico
}

Received 22 December 2017; received in revised form 17 May 2018; accepted 18 May 2018

Available online 2 June 2018

\begin{abstract}
We study the seasonal and interannual variability of the coastal currents along the eastern shelf of the Gulf of Tehuantepec. We use sea level from coastal altimetry distributed by the Centre de Topographie des Océans et de l'Hydrosphère (Toulouse, France). Local validation using tide gauge and hydrographic data indicates that this coastal product measures well the seasonal and interannual scales along this tropical coastline. Long (12 years) time series of altimetry-derived currents, 39-57 km from the coast, reveal new details of the seasonal cycle: currents flow poleward from October to February and equatorward from April to August. Spectral analysis reveals that mesoscale processes are at least as energetic as the seasonal mean. The combination of both determines to a large extent the seasonal and interannual variability of the coastal currents.
\end{abstract}

(c) 2018 COSPAR. Published by Elsevier Ltd. All rights reserved.

Keywords: Poleward flow; Gulf of Tehuantepec; Coastal altimetry

\section{Introduction}

The Gulf of Tehuantepec (GofT) is forced every autumn and winter by strong offshore wind jets known as Tehuanos. They are caused by the atmospheric pressure difference between the Gulf of Mexico and the Pacific. In the winter polar air from the North American plains advance southward reaching the Gulf of Mexico and forcing a wind jet along the Chivela mountain pass, in the Isthmus of Tehuantepec, in southern Mexico (Fig. 1). The wind blows perpendicular to the coast of the GofT and spreads offshore while turning clockwise, following an inertial circle (Clarke, 1998; Steenburgh et al., 1998).

\footnotetext{
* Corresponding author.

E-mail addresses: juan.salazar.ceciliano@una.ac.cr (J. SalazarCeciliano), trasvi@cicese.mx (A. Trasviña-Castro), egonzale@cicese.mx (E. González-Rodríguez).
}

A single event last from two to six days with wind speeds from 20 to $25 \mathrm{~m} \mathrm{~s}^{-1}$ (Romero-Centeno et al., 2003). These jets cause intense cooling in the central part of GofT due to shear-induced vertical mixing (Trasviña et al., 1995). Winter wind events are also responsible for the formation of large $(200 \mathrm{~km}$ in diameter) mesoscale anticyclonic eddies on the Western Gulf (Barton et al., 1993). Early studies suggest that the presence of a single eddy, as opposed to a dipole, is due to the shape of the forcing (Clarke, 1998). A modeling study by McCreary et al. (1989) conclude that nonlinear advection induced by the strong acceleration of the wind is relevant. Trasviña and Barton (2008) report the formation of a dipole in the GofT during the summer of 2000 , forced by steady offshore winds with only weak acceleration. This is consistent with a theoretical study by Crépon and Richez (1982). These authors find solutions for the linear Ekman theory forced by an offshore wind. 


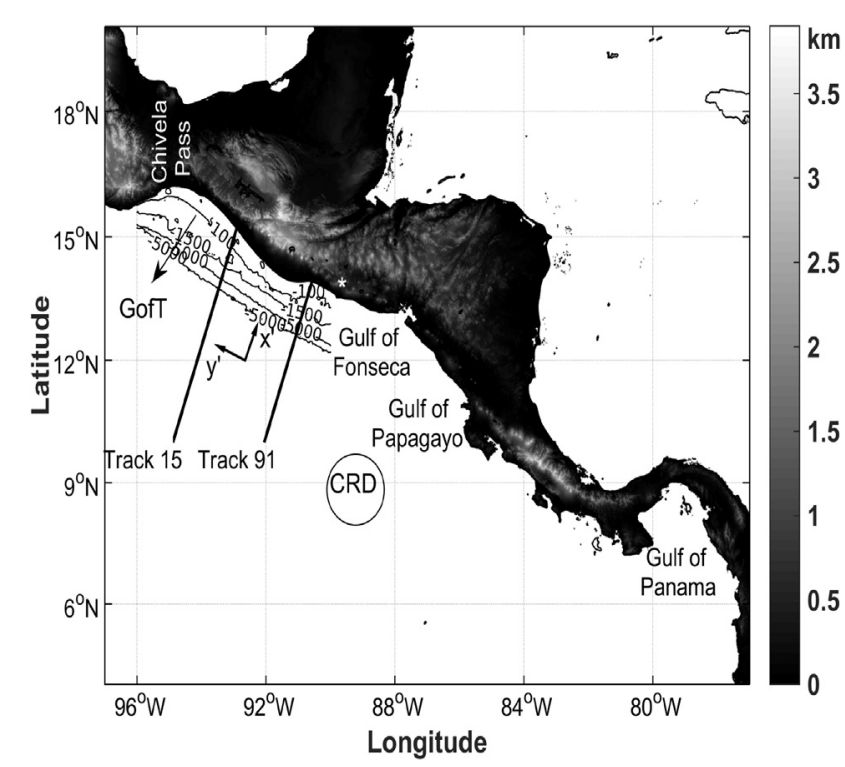

Fig. 1. The study area includes the Gulfs of Tehuantepec (GofT, Mexico), Fonseca (limiting El Salvador, Honduras and Nicaragua) and Papagayo (limiting Nicaragua and Costa Rica). The bathymetry $(\mathrm{m})$ is included near Tehuantepec (form GEBCO (Becker et al., 2009)) to show the width of the continental shelf and the steep continental slope. Altimeter tracks 15 and 91 approach the coast nearly at a 60 angle and will be used to estimate the alongshore component of the geostrophic flow. The tide gauge at Acajutla (El Salvador, marked with a star) is used for validation. CRD marks the center of the Costa Rica Dome.

Here we explore the hypothesis that the winter asymmetric circulation in the GofT is influenced by a buoyancy flow advancing on the GofT due to a poleward coastal flow. Barton et al. (2009) report evidence of such a buoyancy flow in the Eastern Gulf of Tehuantepec. Their hydrographic measurements during experimental campaigns in January 1989 and February 1996 find it from the surface to $50-80 \mathrm{~m}$ depth entering the GofT from the East. It is important to note that previous circulation studies in the region fail to report this coastal flow in winter. Wyrtki (1965) describe a moderately intense poleward current along the coast of Central America from Costa Rica to the GofT throughout the year, except from January to March. Kessler (2006) describes a persistent coastal current from the Costa Rica dome (see Fig. 1) towards the GofT in the dynamic topography but in January-February-March the coastal flow is towards the Equator (Kessler's figure 10). Mesoscale eddies off Central America have been described by Trasviña and Barton (2008), they report offshore propagating speeds of $8-15 \mathrm{~km} \mathrm{~d}^{-1}$. Ballestero and Coen (2004) report the anticyclonic eddies generated in the Gulf of Papagayo and Fonseca that propagate westward without losing identity with propagation speeds around $11 \mathrm{~km} \mathrm{~d}^{-1}$.

In this work we use coastal altimetry to describe the seasonal and interannual variability of the coastal flow on the Eastern shelf of the GofT. We use tide gauge and hydrographic data to validate the sea level data provided by the Centre de Topographie des Océans et de l'Hydrosphère
(CTOH, Toulouse, France). The manuscript is organized as follows. Section 2 describes the data used in this work, in particular the processing of the sea level from coastal altimetry. In Section 3 first we compare and validate the coastal altimetry with in situ data from a tidal gauge and a hydrographic section. Then we continue to describe the seasonal and interannual variability of the coastal circulation based on $10+$ years of coastal altimetry. A final section is dedicated to summarize our findings and conclusions.

\section{Materials and methods}

\subsection{Hydrographic data}

The hydrographic data (temperature, salinity and pressure) was obtained during the oceanographic campaign Tehuano II, carried out from 10 to 27 February 1996 aboard two research vessels: B.O. Altair (SEMAR, Mexico) and the B.O. Francisco de Ulloa (CICESE, Mexico), equipped with a Neil Brown Mark III CTD and a Seabird SBE 9/11 CTD, respectively. Here we show one of the hydrographic sections measured by the B.O. Altair.

\subsection{SLA altimetry product}

We use sea level anomaly (SLA) data from re-processed coastal altimetry developed by the Centre de Topographie des Océans et de l'Hydrosphère ( $\mathrm{CTOH}$, Toulouse). The information is organized along the tracks of the Topex/ Poseidon (1992-2006), Jason I (2001-2013) and Jason II (2008-2013) missions. The product we use has a frequency of $1 \mathrm{~Hz}$, equivalent to one SLA measurement every $7 \mathrm{~km}$ along the track. Each track is repeated every 9. 9156 days. The SLA in the CTOH sea level data is obtained in 2 steps. First the un-corrected sea level anomaly (Eq. (1)) is obtained from the altimeter range $(\mathrm{SSH})$

$S L A_{0}=S S H-M S S H$

By subtracting the 20-year average of the $S S H$ ( $M S S H$ ). Then the SLA is calculated as in Eq. (2)

$S L A=S L A_{0}-T I D E S-D A C_{0}$

where $D A C_{0}$ is the acronym for Dynamic Atmospheric Correction and it includes the atmospheric loading effects. TIDES represents the tidal model that include pole tides, ocean tides and the load tides. CTOH improves the quality of the radar altimeter measurements in the coastal area using several strategies. It starts by discriminating erroneous values based on statistical thresholds for the continental shelf. It then applies tidal corrections in coastal regions using the global model FES2012 (Carrère et al., 2012) adding the solid earth tides corrected as in Cartwright and Tayler (1971). Finally DAC are applied to compensate for the response of the ocean to wind effects and atmospheric pressure forcing, computed in highresolution regional models along the altimeter track from the Mog2D-G model (Carrère and Lyard, 2003). This is 
done by the processing toolbox known as X-TRACK (Roblou et al., 2007, 2011).

In this research we use specific satellite ground tracks from the satellite missions Topex/Poseidon, Jason I and Jason II to estimate geostrophic current anomalies. All these ground tracks cross perpendicularly to the shelf (see for instance Fig. 1). The goal is to describe the temporal variability of the alongshore flow associated to alongtrack SLA slopes. We prefer SLA to absolute dynamic topography because of the uncertainties involved in the estimation of the geoid in the coastal ocean. In Section 3 we test the validity of the SLA-derived currents vs. in situ data.

Several authors have successfully studied the alongshore flow using coastal altimetry. Le Hènaff et al. (2011) on the Cantabrian shelf, Liu et al. (2012) on the West Florida shelf and Valle-Rodríguez and Trasviña-Castro (2017) on the southern Baja California shelf demonstrated that the SLA data distributed by CTOH are appropriate to calculate geostrophic flow anomaly for the study of the coastal circulation.

We estimate the across-track geostrophic current anomaly using the numerical equivalent of the geostrophic momentum equation (Eq. (3)) for a homogeneous ocean

$v^{\prime}=\frac{g}{f} \frac{\Delta h}{\Delta x^{\prime}}$

where $g$ is the local acceleration of gravity, $\Delta h$ is the alongtrack sea level slope, $f$ is the local Coriolis parameter, and $\Delta x^{\prime}$ is the along-track distance between two adjacent points.

Altimetry data contains white noise that can interfere with the calculation of the SLA slope in Eq. (3). We used the optimal difference operator by Powell and Leben (2004) to estimate the derivative of the along-track SLA slope. These authors created an operator (Eq. (4)) to minimize the white noise inherent in the calculation of the derivative of the SLA.

$\Delta_{N t}^{p q}=\sum_{\substack{n=-p \\ \neq \neq 0}}^{q} c_{n}\left(\frac{h_{i+n}-h_{i}}{n \Delta t}\right)$

where $h_{i}$ is the SLA at a point (i) along the track, $\Delta t$ is the sampling interval in seconds, $p$ and $q$ are the number of points before and after the point (i), $N$ is defined as the total number of points $(N=p+q)$ and are the weighting coefficients that satisfy Eq. (5).

$\sum_{\substack{n=-p \\ n \neq 0}}^{q} c_{n}=1$

Powell and Leben (2004) define $T$ as the total number of points in the operator. This is a centered finite-difference operator that includes the point of interest $(T=N+1)$. The choice of $\mathrm{T}$ depends on the half-power wavelength to be smoothed-out. For this we use twice the Rossby deformation radius of the first baroclinic mode $\left(R_{1}\right)$. This is the dominant length scale in the tropical oceans. To estimate $R_{1}$ we use the expression (Eq. (6)) proposed by Gill (1982)

$R_{1}=\frac{\sqrt{\frac{\left(\rho_{2}-\rho_{1}\right) g h_{1}}{\rho_{2}}}}{f}$

where $g$ is the reduced gravity for a 2-layer ocean, $h_{1}$ is the thickness of the upper layer, $f$ is local Coriolis parameter. Using data from hydrographic measurements during experiments Tehuano I and Tehuano II Barton et al. (2009), the length $R_{1}$ for eastern the GofT is about 30 $\mathrm{km}$. Using this length scale in the operator (Eq. (4)) it translates into $T=9(p=4, q=4)$ points. A filter length of 9 points along the satellite ground track spans a total of $56 \mathrm{~km}$. It involves data loss at both extremes of the ground track of about $35 \mathrm{~km}$.

For the time series of estimated currents we use the Burg method to estimate the power spectral density. The use of this technique is ideal for short time series that conform to an autoregressive model and the result has a better frequency resolution than the Fast Fourier Transform (Schlindwein and Evans, 1990). The autoregressive model order $(k)$ required to estimate the power spectral density can be determined using the Akaike information criterion (AIC)

$A I C(k)=\ln \left(\sigma_{k}^{2}\right)+2(k+1) / L$

$\sigma_{k}^{2}=\sigma_{k-1}^{2}\left(1-\left|a_{k k}\right|^{2}\right)$

where $L$ is the number of data samples, $\sigma_{k}^{2}$ is the prediction error power that decreases monotonically with increasing order $k, a_{k k}$ are the Burgs coefficients (must be 1) and $k$ is the model order (Schlindwein and Evans, 1990; Emery and Thomson, 2004). To minimize the value of the $A I C$ we choose $k=40$.

\subsection{Tide gauge}

There are four tide gauges in the GofT but none has data simultaneous with the operation of the altimeters. For this reason we use the tide gauge from Acajutla, El Salvador (white star in Fig. 1). We obtained hourly sea level records from Acajutla from the web page of the University of Hawaii Sea Level Center (http://uhslc.soest.hawaii. edu/data/download/rq).

Tide gauge records usually include ocean tides and the inverted barometer effect. In order to compare with the along-track altimeter data we eliminate the astronomical tide using the prediction from harmonic analysis (Pawlowicz et al., 2002)

residual $=$ tide gange record - tide signals

We then interpolate the residual time series to the times of the SLA data. Finally we remove the inverted barometer effect and other high-frequency signals subtracting the Dynamic Atmospheric Correction (DAC) product distributed by AVISO (https://www.aviso.altimetry.fr/en/ 
data/products/auxiliary-products/atmospheric-corrections. html). Carrère and Lyard (2003) explain that the DAC combines the inverse barometer effect with the highfrequency signal due the wind forcing (shorter than 20 days) to minimize its aliasing effects. This DAC is first spatially interpolated to the specific coordinates of the Acajutla tide gauge and next interpolated in time to match $\mathrm{CTOHs}$ times.

sla tide gauge $=$ residual $-D A C$

\section{Results and discussion}

\subsection{Validation}

In this section we compare SLA from altimetry with two independent sets of observations. The first is in situ SLA from the tide gauge at Acajutla (Fig. 1) for the periods 1993-2002 and 2009-2013. The comparison is with the time series of the nearest altimetry track (91, see Fig. 1) at $33.1 \mathrm{~km}$. The second set of observations is composed of hydrographic measurements obtained during a field experiment on 25-26 February 1996 (see Section 2.1), to be compared with across-track geostrophic current anomaly along the track number 15, observed on 25 February 1996.

First we compare the SLA from altimetry on track 91 $(33.1 \mathrm{~km}$ from the coast) with SLA from the Acajutla tide gauge, from 1993 to 2001 (Fig. 2). The tide gauge measures sea level at the coast while the altimetry data contains sea level variability in the shelf adjacent to the tide gauge. Despite this, both time series follow the same seasonal and interannual cycles for the nearly 9-years being compared. The interannual variability contains identifiable phenomena such as the sea level increase associated to the passage of remotely forced coastal Kelvin waves during El Niño 1997-1998 (McPhaden, 1997). The differences observed in the high frequency variations between both time series can be attributed to background noise in the SLA from altimetry due to wavelengths shorter than $7 \mathrm{~km}$, or to the differences in location and measurement method between time series.

The Pearson correlation coefficients between altimetry SLA and the tide gauge time series are shown in Table 1. The table contains correlation coefficients at 5 sites, 17.2-101.1 km off the coast for the TOPEX (1993-2002) and Jason I and II (2009-2013) periods. All correlation coefficients are positive with a significance level of $95 \%$ and a mean square error $\mathrm{O}(0.09 \mathrm{~m})$. Maximum correlation is attained with the altimetry time series measured $33.1 \mathrm{~km} / 17.2 \mathrm{~km}$ off the coast for the first/second period. All correlations are of the same magnitude in the first $50 \mathrm{~km}$ and then decrease offshore, as reported by Bouffard et al. (2008) off the coastal of the northwestern Mediterranean Sea.

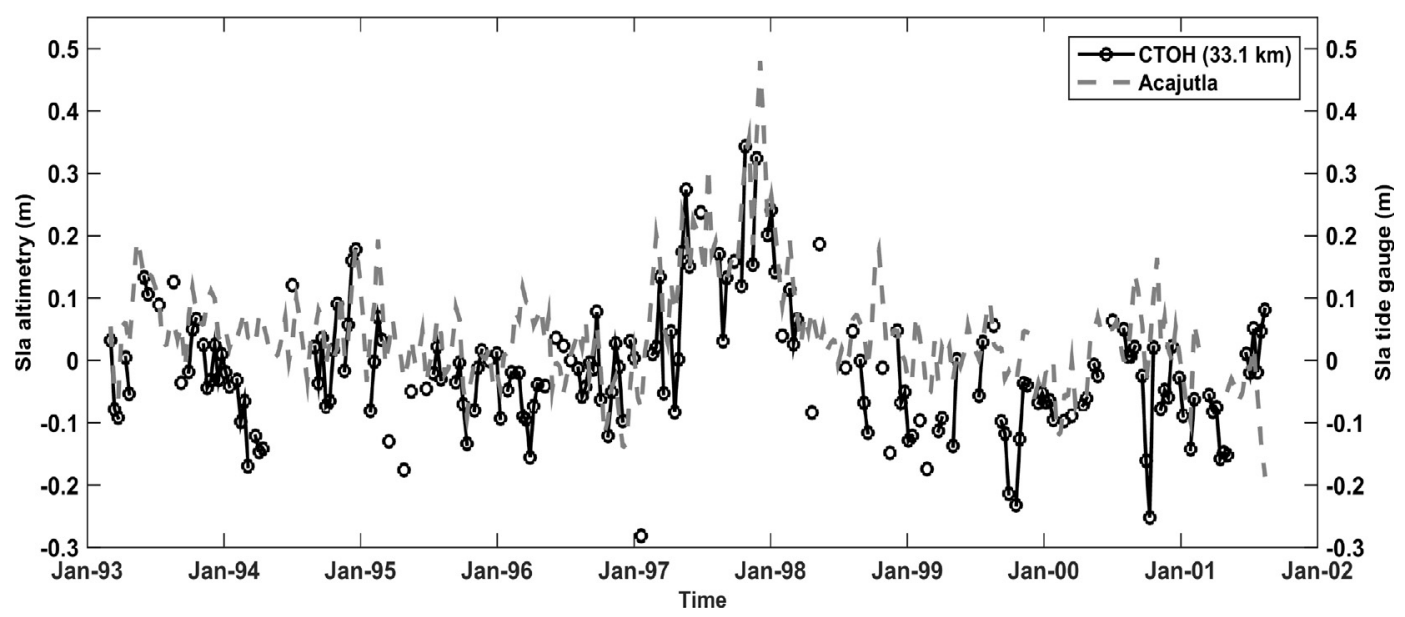

Fig. 2. SLA time series at the Acajutla (El Salvador) tidal gauge, compared to the SLA time series on track 91, $33.1 \mathrm{~km}$ from the coast (from CTOH).

Table 1

Statistics between SLA of the tidal gauge at Acajutla and the altimetry ground track number 91. Acronyms D, P, S, RMS and Np stand for distance to the coast, Pearson correlations coefficients, significance level (95\%), mean square error and number of points used for the estimate.

\begin{tabular}{|c|c|c|c|c|c|c|c|c|}
\hline \multirow[t]{2}{*}{$\mathrm{D}(\mathrm{km})$} & \multicolumn{4}{|c|}{ First period (1993-2002) } & \multicolumn{4}{|c|}{ Second period (2009-2013) } \\
\hline & $\mathrm{P}$ & $S$ & RMS (m) & $\mathrm{Np}$ & $\mathrm{P}$ & $\mathrm{S}$ & RMS (m) & $\mathrm{Np}$ \\
\hline 17.2 & 0.6346 & $1.5 \mathrm{e}-10$ & 0.0966 & 150 & 0.5020 & $2.5 e-7$ & 0.0949 & 94 \\
\hline 33.1 & 0.6643 & $3.7 e-24$ & 0.0946 & 234 & 0.4962 & $1.1 \mathrm{e}-7$ & 0.0836 & 102 \\
\hline 73.0 & 0.6167 & $7.6 \mathrm{e}-29$ & 0.1061 & 262 & 0.2887 & 0.0036 & 0.1004 & 100 \\
\hline 101.1 & 0.5620 & $1.2 \mathrm{e}-23$ & 0.1078 & 267 & 0.2622 & 0.0091 & 0.0981 & 98 \\
\hline
\end{tabular}


In Fig. 3 we show the comparison between geostrophic currents from altimetry and those measured simultaneously along a hydrographic section below the track. Altimetry data is estimated along track 15, on 25 February 1996 (Fig. 3a) simultaneous with the hydrographic section measured from 25 to 26 February 1996 (Fig. 3b). The altimetry in Fig. 3a shows a strong poleward (positive) flow in the first $60 \mathrm{~km}$ from the coast with a weak equatorward (negative) flow offshore. This coincides with the sign of the flow in the upper $50 \mathrm{~m}$ of the hydrographic section and with the sign change between 60 and $70 \mathrm{~km}$ offshore (Fig. 3b). This is consistent with SLA from altimetry reflecting sea level changes caused by the upper-ocean dynamics of this tropical ocean.

The coastal altimetry data from $\mathrm{CTOH}$ used here measures sea level at $1 \mathrm{~Hz}$ along the track (every $7 \mathrm{~km}$ ) and it contains the signature of the abundant mesoscale eddies reported for this area in the literature. Due to this potential difficulty it is important to note the similarities between the tide gauge and hydrographic data with CTOH's coastal altimetry time series. Such agreement validates its usefulness in our study area.

\subsection{Geostrophic currents from coastal altimetry}

The available coastal altimetry time series can be separated into four periods:

1. From 1992 to 2001 only Topex/Poseidon in operation.

2. From 2001 to 2006 with Topex/Poseidon and Jason 1 in operation.

3. From 2006 to 2008 with only Jason 1 in operation.

4. From 2008 to 2013 with Jason 1 and 2 in operation.

For the geostrophic current time series we show the 12-year period from 2002 to 2013 when two altimetry satellites are in operation most of the time. Fig. 4 shows across-track geostrophic current anomaly in Fig. 4 is based on measurements made along satellite ground track 15 (see Fig. 1).

The across-track geostrophic current anomaly in Fig. 4 is based on measurements made along satellite ground track 15 (see Fig. 1). Currents are estimated every 10 days and therefore we can only resolve periods of 20 days or longer. The nearest distance where we can estimate currents is $39 \mathrm{~km}$ (bottom depth of $60 \mathrm{~m}$ ) due to the data processing. In Fig. 4a we show the original and the filtered time series (using a $120 \mathrm{~d}$ low-pass). The original series in Fig. 4a contains the variability due to the passage of mesoscale eddies. They are responsible for the sudden changes in direction of the alongshore flow. The filtered series (smooth black line) in Fig. 4b is included to highlight the seasonal and interannual variability. The seasonal pattern contains poleward flow in most winters and equatorward flow in the summer. In the time series of Fig. $4 \mathrm{~b}$ persistent poleward alongshore currents occur on the eastern continental shelf of the GofT in 9 of 11 winters inspected. In the interannual scale the record includes three distinct periods. From 2002 to 2007 the alongshore currents follow a regular seasonal variation (poleward/equatorward in winter/summer). From 2008 to 2009 the flow is weak $\left(0.2 \mathrm{~m} \mathrm{~s}^{-1}\right.$ or less), the previous pattern is disrupted and neither winter nor summer show a strong mean flow. At the same time mesoscale variability reach a maximum in the period with intense and sudden changes in direction, as shown in the original time series (Fig. 4a). This coastal region is subject to remote forcing during ENSO events, during this period however, both the Pacific Decadal Oscillation (PDO) and the Multivariate ENSO (MEI) index are in a cool phase. This unusual period appears to be the result of atypical mesoscale activity. A third period starts in the winter of 2009-2010 and continues to the end of the series in 2013 with a return to the typical seasonal pattern.

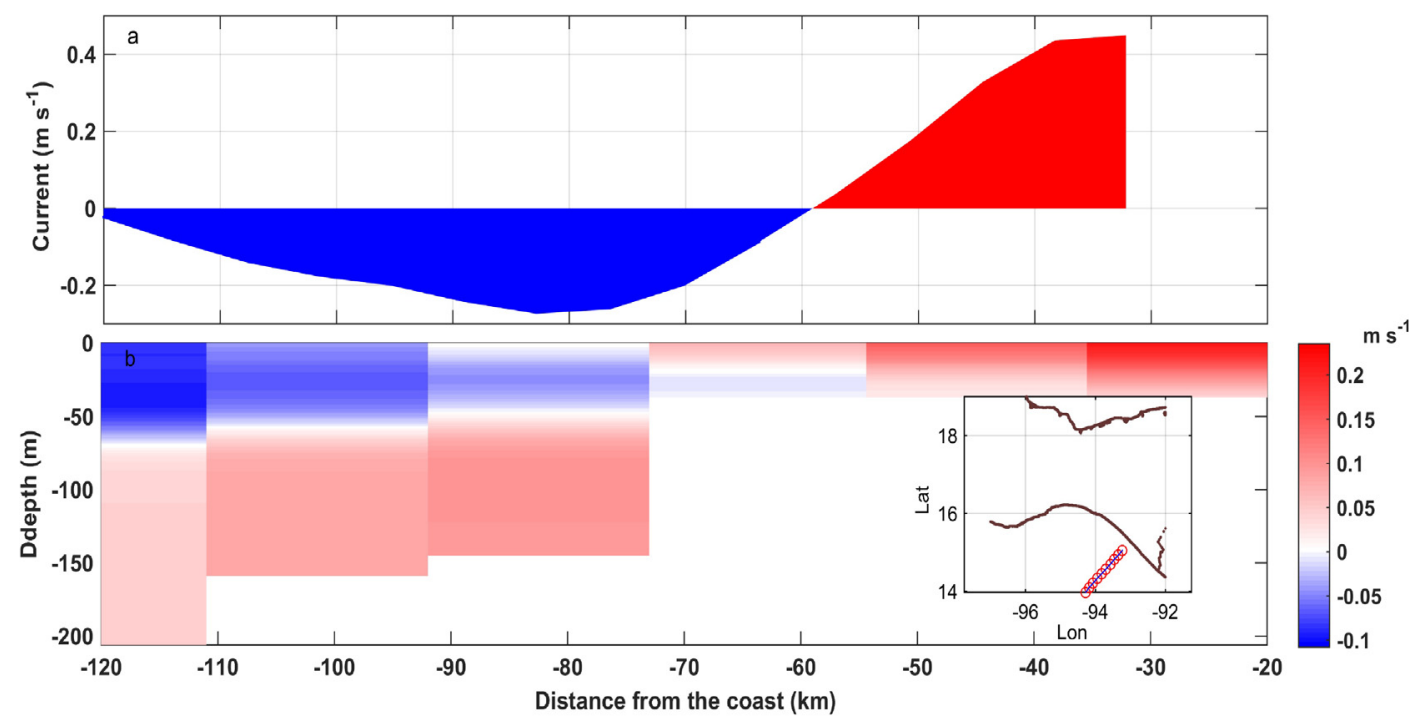

Fig. 3. Alongshore-geostrophic currents for the eastern Gulf of Tehuantepec: (a) from coastal altimetry across track 15, on 25 February 1996 and (b) from a hydrographic section measured from 25 to 26 February 1996. 

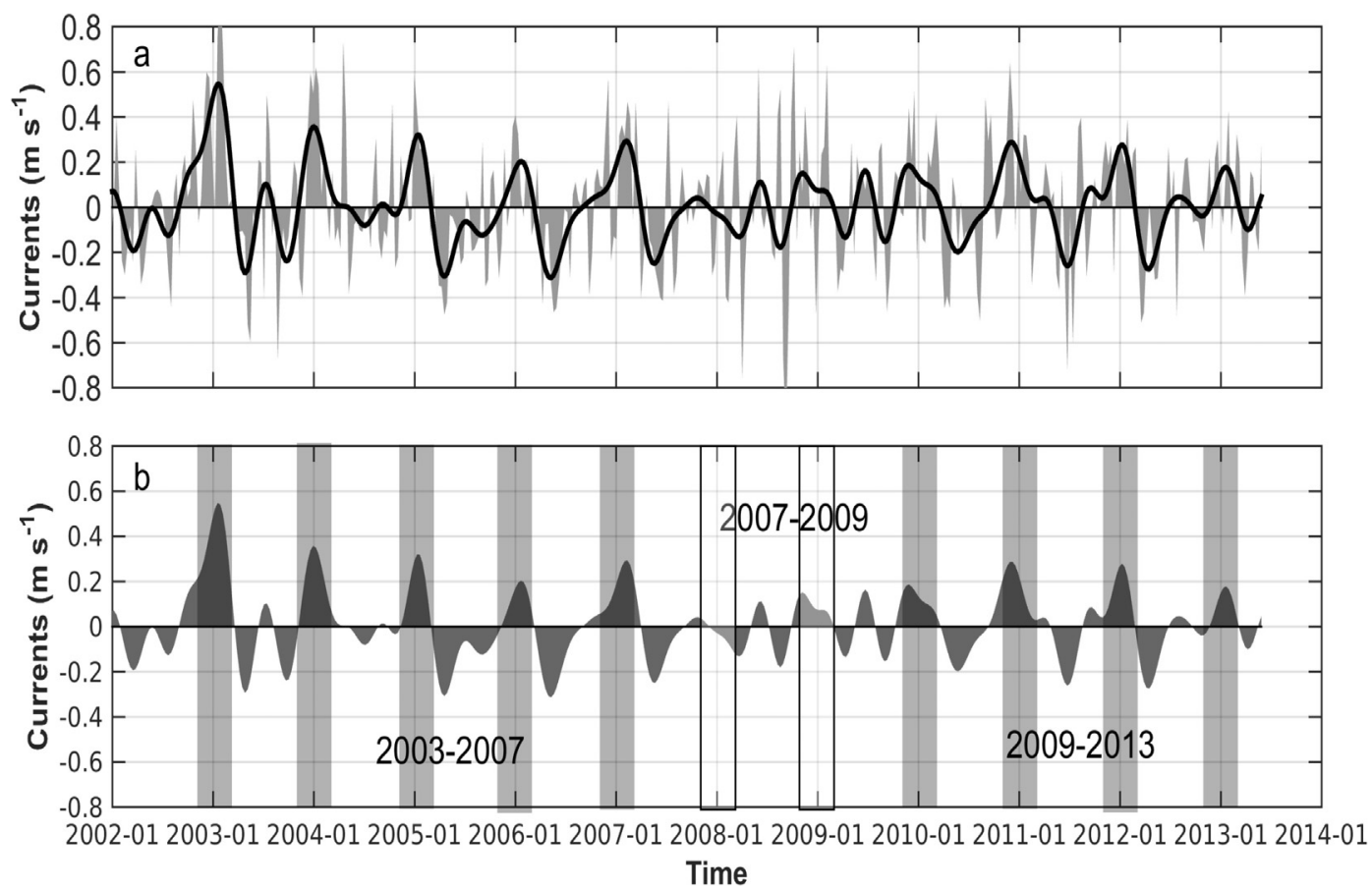

Fig. 4. Time series of alongshore-geostrophic (across-track) current anomaly $39 \mathrm{~km}$ off the eastern shelf of the Gulf of Tehuantepec on track 15 , from 2002 to 2013. (a) Original (gray filled area) and filtered time series using a $120 \mathrm{~d}$ low-pass (solid line). (b) The filtered time series with winter poleward flow highlighted (grayrectangles). The dates mark three distinct interannual periods.

To highlight the importance of the high-frequency variability in determining the seasonal pattern, Fig. 5 shows all the typical years superimposed, with the mean flow superimposed (gray shaded curve). The seasonal cycle can be characterized as

- Poleward alongshore flow from October to February with mean speed of $0.07-0.25 \mathrm{~m} \mathrm{~s}^{-1}$ (maximum in January).

- Equatorward alongshore flow from April to August with mean speed of $0.08-0.19 \mathrm{~m} \mathrm{~s}^{-1}$ (maximum in April).

- March and September are transitional months.

- Maximum alongshore flow speeds in individual features are quite significant and can reach $0.8 \mathrm{~m} \mathrm{~s}^{-1}$.
Fig. 6 show the spectral density of the alongshore currents (track 15) at 3 distances to the coast: 38,44 and $51 \mathrm{~km}$. The continuous line is the spectra nearest to the coast $(38 \mathrm{~km})$ containing a region of peaks between 20 and 40 days. We attribute this to the passage of mesoscale eddies. Several authors report the presence of largo mesoscale eddies in the coastal region. Trasviña and Barton (2008) report eddies moving at speeds between 8 and 15 $\mathrm{km} \mathrm{d}^{-1}$. Barton et al. (2009) describe such mesoscale features interacting with coastal currents. These peaks are induced by the passage of mesoscale eddies propagating through the coastal region at different translation speeds. Another interesting feature is the peak at 50 days that grows offshore by a factor of 3 . This is consistent with large-scale forcing, although its origin is unclear. Three

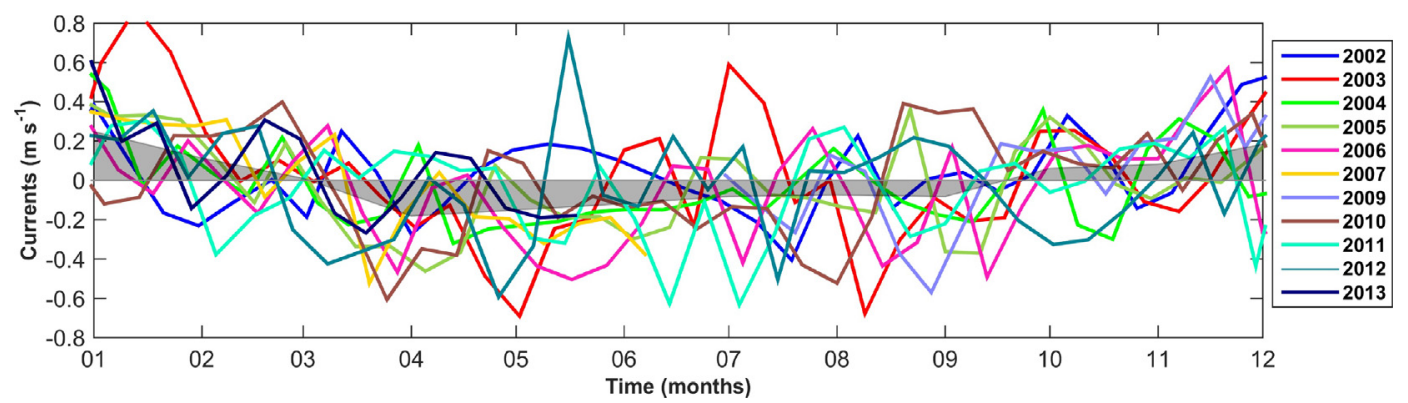

Fig. 5. Along-shore current from coastal altimetry (track 15, $39 \mathrm{~km}$ offshore) on the eastern shelf of the Gulf of Tehuantepec. All years in the inset are shown superimposed as a single year. The mean monthly flow is shown as a shaded curve (light gray). It indicates poleward flow in the months of January, February, November and December. 


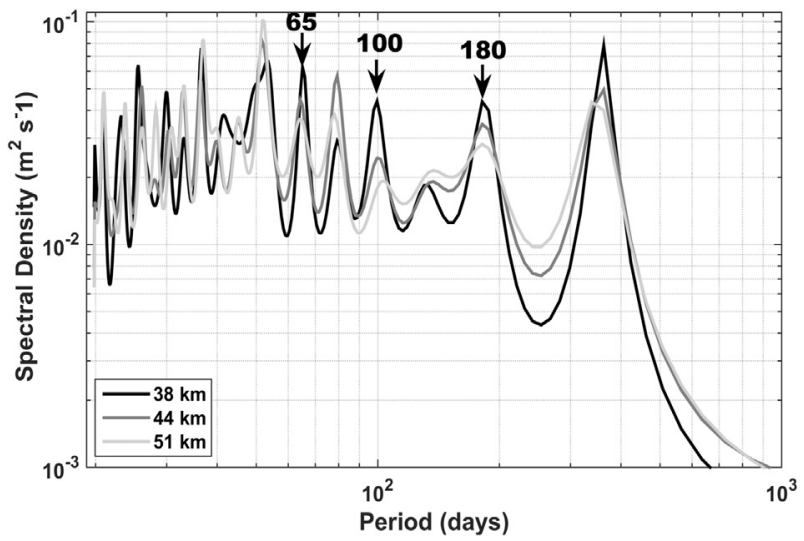

Fig. 6. Spectrograms of across-track geostrophic current anomaly on track 15 (38, 44 and $51 \mathrm{~km}$ from the coast, see the inset). Arrows mark those peaks where power decreases offshore. The period in days is also indicated.

peaks at 65, 100 and 180 days, all of which diminish in intensity offshore, are consistent with the passage of coastally trapped waves (CTWs). A thorough discussion of CTWs is beyond the scope of this paper. However, it is important to note that Flores-Vidal et al. (2014) report evidence of CTWs in the GofT, forced by a negative sea level anomaly induced by the offshore winds of the Gulf of Panama. They estimate travel times of approximately 60 days to the GofT. Also, Strub and James (2002) report coastal sea-level anomalies in southern Mexico during May-June propagating poleward towards the entrance to the Gulf of California. Zamudio et al. (2008) also show that CTWs are responsible for sea surface height variability along Central America and Mexico during winter and early spring.

In the three spectra the most important energy peaks are found at 363 days (annual), 65 days (bi-monthly) and near $40 \mathrm{~d}$. The annual and semi-annual peaks represent the seasonal changes that dominate the mean flow in the time series previously discussed (Figs. 4 and 5). The more important is the annual peak and, at the location closest to the coast, it is about the same magnitude as the shortperiod (40 days or less) variability.

\section{Conclusions}

We present a validation of CTOHs coastal altimetry in a tropical ocean. The comparison with 10 years (1993-2003) of sea level from a tidal gauge shows good agreement and maximum correlation at the first available offshore altimetry site. This result indicates that the altimetry sea-level time series can be used to estimate geostrophic currents. Furthermore, we also obtain good agreement between currents from hydrography and geostrophic currents from coastal altimetry. In-situ hydrography indicates a change of direction in the flow around $70 \mathrm{~km}$ off the coast, consistent with geostrophic flow estimates from coastal altimetry. We conclude that the $1 \mathrm{~Hz}$ coastal altimetry product from
$\mathrm{CTOH}$ it is capable of measuring the seasonal to interannual variability of the coastal currents in our region.

In the pioneer study by Wyrtki (1965) he reports the presence of a coastal poleward current along the Central American coast, from August to December: the Costa Rica Coastal Current (CRCC) flowing from the Costa Rica Dome $\left(9^{\circ} \mathrm{N}\right)$ to the eastern shelf of the GofT $\left(15^{\circ} \mathrm{N}\right)$. More recently Kessler (2006) reports the mean circulation using bathythermograph data. He describes the CRCC as a northwestward stationary current between the Costa Rica Dome and the Gulf of Tehuantepec with a mean speed of $0.20 \mathrm{~m} \mathrm{~s}^{-1}$. This author indicates that the CRCC is present during summer and spring but absent or weak the rest of the year. Our analysis based on 12 years of sea level from $\mathrm{CTOH}$ coastal altimetry describes a somewhat different picture. We find a predominantly poleward coastal circulation from October to February (autumn and early winter months) with typical speeds of 0.07 $0.25 \mathrm{~m} \mathrm{~s}^{-1}$ (maximum in January) and maximum of 0.8 $\mathrm{m} \mathrm{s}^{-1}$. The current is equatorward from April to August (spring to mid-summer) with typical values of $0.08-0.19$ $\mathrm{m} \mathrm{s}^{-1}$ (maximum in April) and up to $0.8 \mathrm{~m} \mathrm{~s}^{-1}$. This is modulated by intense mesoscale eddies and the passage of CTWs. Energetic eddies off the eastern shelf of the GofT have been described by Ballestero and Coen (2004) and Trasviña and Barton (2008). These authors report eddies generated in the Gulfs of Papagayo and Fonseca that propagate westward traversing the study area with speeds of 8 $15 \mathrm{~km} \mathrm{~d}^{-1}$. The passage of CTWs is reported by FloresVidal et al. (2014). The spectral analysis of the currents reveals that the flow results from a combination of stationary currents (annual and semi-annual in period), intraseasonal process (bimonthly) and energetic mesoscale eddies present. The annual and 40 days components are similar in power near the coast.

The anomalous period from 2007 to 2009 poses a new question. Weak mean flow coexists with current variability associated to intense mesoscale. And this occurs when both the PDO and MEI indices are in a cool phase. This motivates a future study of the connections between remote atmospheric forcing in the region, eddy generation and the mean coastal circulation.

\section{Acknowledgments}

We wish to express our gratitude to Ph.D. José Luis Ochoa de la Torre and Ph.D. María Lucila del Carmen Lares Reyes, their comments greatly contributed to the quality of the manuscript. Altimetry dataset processed with X-TRACK were developed, validated, and distributed by the CTOH/LEGOS, France. This work was supported by the Mexican Ministry of the Environment and Natural Resources and the National Council for Science and Technology. This work is also sponsored by the CICESE La Paz, the Oceanology Division of CICESE and the National University of Costa Rica. We also wish to thank the anonymous reviewers for their valuable comments. 


\section{References}

Ballestero, D., Coen, J., 2004. Generation and propagation of anticyclonic rings in the Gulf of Papagayo. Int. J. Remote Sens. 25 (11), 2217-2224.

Barton, E.D., Argote, M., Brown, J., Kosro, P., Lavín, M., Smith, R., Robles, J., Trasviña, A., Vélez, H., 1993. Supersquirt: dynamics of the Gulf of Tehuantepec, Mexico. Oceanography 6 (1), 23-30.

Barton, E.D., Lavín, M.F., Trasviña, A., 2009. Coastal circulation and hydrography in the Gulf of Tehuantepec, Mexico, during winter. Cont. Shelf Res. 29 (2), 485-500.

Becker, J.J., Sandwell, D.T., Smith, W.H.F., Braud, J., Binder, B., Depner, J., Fabre, D., Factor, J., Ingalls, S., Kim, S.H., Ladner, R., 2009. Global bathymetry and elevation data at 30 arc seconds resolution: SRTM30 PLUS. Mar. Geod. 32 (4), 355-371.

Bouffard, J., Vignudelli, S., Cipollini, P., Menard, Y., 2008. Exploiting the potential of an improved multimission altimetric data set over the coastal ocean. Geophys. Res. Lett. 35 (10).

Carrère, L., Lyard, F., 2003. Modeling the barotropic response of the global ocean to atmospheric wind and pressure forcing comparisons with observations. Geophys. Res. Lett. 30 (6). https://doi.org/10.1029/ 2002GL016473.

Carrère, L., Lyard, F., Cancet, M., Roblou, L., Guillot, A., 2012, September. FES 2012: a new tidal model taking advantage of nearly 20 years of altimetry measurements. In: Ocean Surface Topography Science Team 2012 meeting, Venice-Lido, Italy.

Cartwright, D.E., Tayler, R.J., 1971. New computations of the tide generating potential. Geophys. J. Int. 23 (1), 45-73.

Clarke, A.J., 1998. Inertial wind path and sea surface temperature patterns near the Gulf of Tehuantepec and Gulf of Papagayo (1978-2012). J. Geophys. Res.: Oceans 93 (C12), 15491-15501.

Crépon, M., Richez, C., 1982. Transient upwelling generated by twodimensional atmospheric forcing and variability in the coastline. J. Phys. Oceanogr. 12 (12), 1437-1457.

Emery, W.J., Thomson, R.E., 2004. Data Analysis Methods in Physical Oceanography, second ed. Elsevier, Amsterdam.

Flores-Vidal, X., Durazo, R., Zavala Sansn, L., Flament, P., Chavanne, C., Ocampo-Torres, F.J., Reyes Hernndez, C., 2014. Evidence of inertially generated coastal-trapped waves in the eastern tropical Pacific. J. Geophys. Res.: Oceans 119 (5), 3121-3133.

Gill, A.E., 1982. Atmosphere-ocean Dynamics, vol. 30. Academic Press, pp. 189-208.

Kessler, W.S., 2006. The circulation of the eastern tropical Pacific: a review. Prog. Oceanogr. 69 (2), 181-217.

Le Hènaff, M., Roblou, L., Bouffard, J., 2011. Characterizing the Navidad current interannual variability using coastal altimetry. Ocean Dyn. 61 (4), 425-437. https://doi.org/10.1007/s10236-010-0360-9.

Liu, Y., Weisberg, R.H., Vignudelli, S., Roblou, L., Merz, C.R., 2012. Comparison of the X-TRACK altimetry estimated currents with moored ADCP and HF radar observations on the West Florida Shelf. Adv. Space Res. 50 (8), 1085-1098. https://doi.org/10.1016/j. asr.2011.09.012.

McCreary, J.P., Lee, H.S., Enfield, D.B., 1989. The response of the coastal ocean to strong offshore winds: with application to circulations in the Gulfs of Tehuantepec and Papagayo. J. Mar. Res. 47 (1), 81-109.

McPhaden, M.J., 1997. Genesis and evolution of the 1997-98 El Niño. Science 283 (5404), 950-954.

Pawlowicz, R., Beardsley, B., Lentz, S., 2002. Classical tidal harmonic analysis including error estimates in MATLAB using T_TIDE. Comput. Geosci. 28 (8), 929-937.

Powell, B.S., Leben, R.R., 2004. An optimal filter for geostrophic mesoscale currents from along-track satellite altimetry. J. Atmos. Ocean. Technol. 21 (10), 1633-1642.

Roblou, L., Lyard, F., Le Hènaff, M., Maraldi, C., 2007. X-track, a new processing tool for altimetry in coastal oceans. In: ESA ENVISAT Symposium, Montreux, Switzerland, April 23-27, 2007. ESA SP, 636.

Roblou, L., Lamouroux, J., Bouffard, J., Lyard, F., Le Hènaff, M., Lombard, A., Marsaleix, P., De Mey, P., Birol, F., 2011. Postprocessing altimeter data towards coastal applications and integration into coastal models. In: Coastal Altimetry. Springer, Berlin Heidelberg, pp. 217-246. https://doi.org/10.1007/978-3-642-12796-0_9.

Romero-Centeno, R., Zavala-Hidalgo, J., Gallegos, A., O'Brien, J.J., 2003. Isthmus of Tehuantepec wind climatology and ENSO signal. J. Clim. 16 (15), 2628-2639.

Schlindwein, F.S., Evans, D.H., 1990. Selection of the order of autoregressive models for spectral analysis of Doppler ultrasound signals. Ultrasound Med. Biol. 16 (1), 81-91.

Steenburgh, J., Schultz, D., Colle, A., 1998. The structure and evolution of gap outflow over the gulf of Tehuantepec, Mexico. Mon. Weather Rev. 126 (10), 2673-2691.

Strub, P.T., James, C., 2002. Altimeter-derived surface circulation in the large-scale NE Pacific Gyres.: Part 2: 1997-1998 El Niño anomalies. Prog. Oceanogr. 53 (2-4), 185-214.

Trasviña, A., Barton, E.D., Brown, J., Velez, H.S., Kosro, P.M., Smith, R.L., 1995. Offshore wind forcing in the Gulf of Tehuantepec, México: the asymmetric circulation. J. Geophys. Res. 100 (C10), 20649-20663.

Trasviña, A., Barton, E.D., 2008. Summer circulation in the Mexican tropical Pacific. Deep Sea Res. Part I 55 (5), 587-607.

Valle-Rodríguez, J., Trasviña-Castro, A., 2017. Poleward currents from coastal altimetry: the west coast of Southern Baja California, Mexico. Adv. Space Res. 59 (9), 2313-2324.

Wyrtki, K., 1965. Surface currents of the eastern tropical Pacific Ocean. Int.-Am. Trop. Tuna Commiss. Bull. 9 (5), 63-97.

Zamudio, L., Metzger, E.J., Hogan, P.J., 2008. A note on coastally trapped waves generated by the wind at the Northern Bight of Panamá. Atmósfera 21 (3), 241-248. 